\title{
Research on Class Management Under the Background of New Media
}

\author{
Li Bin-bin \\ China West Normal University, \\ Nanchong, Sichuan,637002 \\ Email: 1bb0929@sina.cn
}

Keywords: New media; Colleges and Universities; Class management

\begin{abstract}
With the reform and development of information technology, new media has been widely used in various fields, the impact on people's daily lives is more and more big, the current application of Chinese universities in the information communication technology began a period of rapid development, new media constantly in class management in Colleges and universities in the dominant position, the traditional college class management mode has a great impact. Therefore, based on the analysis of existing class management under the background of new media in the problems, puts forward corresponding solving strategies on how to correctly use the new media technology in class management, hoping to provide a reference for the further improvement of class management level.
\end{abstract}

\section{Introduction}

Although the new media still has many problems and deficiencies in the class management of colleges and universities, as a new media and technology model, it must have its value and advantages. In the traditional class management mode, such as information exchange and transfer is not smooth, the new media technology can effectively solve, and on this basis, also appeared a lot of new ways of class management, strengthen the communication with students, promote the teaching of high speed information transmission. Therefore, we should pay enough attention to the class management under the background of new media, so as to effectively improve the efficiency of class management.

\section{Problems faced by class management in the context of new media}

\subsection{The emergence of new media makes some students addicted to the network}

Under the background of rapid development of new media technology, with the continuous improvement of the economic level, the Internet equipment represented by PC computers and mobile phones is becoming more and more popular.Therefore, the rapid popularization of the network and the groups of college students, the diversity of the world and temptation, the students rely on the network for more and more serious, social warning "bow" and "mobile phone control" phenomenon in college students especially ${ }^{[1]}$.For some students with poor control ability, the wonderful and mysterious world of Internet makes them indulge in it, they spend a lot of time, money and energy in the network world.This leads to communication between them and the students and teachers communicate less and less, for academic attention has also gradually reduced, this should be full of vitality, colorful university life is the network world to occupy, did not participate in the interest and passion for school activities organized by the people of the state of no vitality and the activity of college students, but more than a lot of malaise and decadence.Therefore, the students' addiction to the network makes the class management work facing severe challenges, this situation has spread to the classroom trend. According to the survey, half of the students use mobile phones and other network devices to learn outside the classroom, although the school explicitly asked students to prohibit the use of mobile phones in the classroom, but little effect. 


\subsection{The development of new media impacts the traditional class management mode}

The continuous development of new media technology, network, mobile phones and other equipment derivative goods widely used, the traditional class management model has caused a strong impact. The use of new media for class management, not only broadens the work space of college counselors, but also for class management timeliness has greatly improved. There is a trade-off, the teachers and students under the background of new media discourse are dispersed and weakened, although the spread of new media for the class information is very large, but because of its dispersion and uncertainty, these are not conducive to the formation of class cohesion and centripetal force, and also affects the class the effect of management.

\section{Strategy analysis of improving class management in the context of new media}

\subsection{Strengthening the ideological and political education of students}

Class is an important place to gather students and produce teaching and education. Therefore, class plays a vital role in the ideological and political education of students.Due to the strengthening of the class management and strengthen students' Ideological and political education objective is the same, is to realize the "striving for excellence, all talent teaching objectives, a series of methods used in the ideological and political education work and strengthen the class management method is the same, even is the same, a in between the two results are complementary and closely related to ${ }^{[2]}$.Therefore, the primary task of strengthening class management work is to strengthen students' Ideological and political education work, let them organically, so as to achieve the purpose of teaching and teaching objectives, and jointly promote the efficiency of class management work.

\subsection{Building information platform through new media technology software}

Through the use of QQ, micro-blog, WeChat and other new media platform to build class information platform, and constantly improve the efficiency of class daily management and the level of information management. For example, in recent years in Colleges and universities is very popular class management system software - love class software.It is specially created for college counselors is a management software, has the characteristics of management tools according to the work of counselors need to create a campus, this software mainly includes: mail list, class attendance management, class management, guestbook leave the announcement, etc., to promote the instructor's class management this work through management software, and set up a class information management platform through such management software, so that instructors can understand the first time students' psychological development and dynamic demand, thereby reducing the pressure of the work of counselors.

\subsection{Scientific and rational use of new media technology to strengthen communication between teachers and students}

Teachers need to improve their management level, to keep pace with the times, strengthen the absorption of advanced things, make full use of modern information communication tools (QQ, WeChat, micro-blog, email etc.) to form a triangle exchange of information chain, namely the parent - Teacher - student,so that between the three can communicate in time, communicate with each other. This provides a convenient condition for counselors to collect and understand students' daily life and learning information, and provides the basis and guarantee for the effectiveness of message transmission between Counselors and parents. Through such a platform to strengthen the communication with students' hearts, and enhance the distance between students, so as to provide a basic guarantee for class management.

\section{Peroration}

With the continuous development of social economy and science and technology, under the new media era, everyone can express themselves independently, which is full of opportunities and also 
faces great challenges for class management in Colleges and universities. As policymakers and leaders of class management, we should fully grasp the opportunity, the development of the times, follow the law of development of new media constantly adjust the class management mode, change the traditional management concept, fully understand and grasp the technical characteristics of new media, play a positive role in the new media, provide better service for class management use of new media technology.

\section{References}

[1]Yang Sheng.Challenges and Countermeasures of class management in Colleges and Universities under the new media environment [J]. Western Quality Education, 2017, 3 (12): 68-69.

[2]He Hui.Analysis of how counselors use new media to manage class [J]. Global Market, 2017 (5): 89-89.

[3]Li Bin-bin,Long Han-wu. Exploration on the Fine Management of College Classes under the Background of New Media[J]. International Journal of Liberal Arts and Social Science,2016(9):11-16. 